\title{
Erratum to: Reclamation of Arid Lands
}

\section{Erratum to:}

M. Jafari et al., Reclamation of Arid Lands, Environmental Science and Engineering, https://doi.org/10.1007/978-3-31954828-9

The original version of the book was inadvertently published prematurely before incorporating the final corrections due to an error in the production process. The version supplied here has been corrected and approved by the author.

The updated online version of the book can be found at https://doi.org/10.1007/978-3-319-54828-9 